\title{
"GRITAR, DEJAR LOS TONOS MENORES, TONO MAYOR SOSTENIDO”: NOTAS SOBRE LA APARICIÓN E INSTALACIÓN DE LA BRECHA DE MERCEDES VALDIVIESO
}

\author{
Gabriela Alburquenque \\ Universidad de Chile \\ Santiago, Chile \\ g.albqnq@gmail.com
}

\begin{abstract}
Nombrar es el comienzo, nombrar es reclamar para sí, apropiarse. Estamos hablando, estamos escribiendo para construir un mundo más espacioso donde nuestro testimonio sea creído, no increíble.

FERNANDA TRÍAs ${ }^{1}$
\end{abstract}

La brecha (1961) comienza con una advertencia: "El personaje de esta novela no tiene nombre, pero podría ser el de cualquier mujer de nuestra generación" (Valdivieso, La brecha 7). Estas palabras, tres líneas apenas ${ }^{2}$, permiten tomar una primera hebra al momento de desenmarañar el trayecto de algunos de los nudos presentes en la aparición e instalación de la novela debut de Mercedes Valdivieso en el campo cultural chileno. Estoy hablando del signo mujer enunciado en la advertencia, el cual se emplea no solo para signar la subjetividad y rol de la protagonista del relato -como es evidente por lo que el enunciado advierte- sino también al libro en su proceso de

1 (Trías min. 58:46).

2 En su primera edición, la advertencia está diagramada con cortes que parten la frase en tres líneas y no dos como ocurre en este texto, organizándola de la siguiente manera: "El personaje de esta novela no tiene/ nombre, pero podría ser el de cual-/ quier mujer de nuestra generación" (ibid.). 
instalación en la institucionalidad literaria de mediados del siglo XX en la llamada "literatura de mujeres".

Estas notas persiguen cruces, intersecciones y encuentros entre las estrategias estéticas y políticas con arranque feminista ${ }^{3}$ presentes en el momento de producción, publicación, difusión y recepción de la novela en el Chile de 1961, con el propósito de hacer visibles una serie de condiciones materiales y abstractas que determinan el ingreso de Mercedes Valdivieso al campo cultural chileno de mediados del siglo XX y su posterior legitimación en el mismo, siendo esta última una a medias, coartada, pues ocurre tras un proceso de sujeción de la autoría de la escritora respecto a su rol a/signado socialmente bajo los parámetros y herramientas de sujeción de la identidad, como lo es la herramienta del género ${ }^{4}$, que, al decodificar el relato del cuerpo tras la escritura -un cuerpo que existe de cara a una cultura que universaliza lo masculino como la neutralidad, la norma y todo "lo otro", todo lo demás, como lo particular; lo nominado como lo otro, de hecho- signa también la correspondencia - $\mathrm{O}$ no- de ese cuerpo material con el espacio virtual en el que se instala: en una relación de tutelaje o no de las escritoras con el domicilio literario 5 .

De cierta manera, estos apuntes vuelven a la pregunta que Nelly Richard nos lanzó ya en 1987 y, que otras colegas ya han retomado, sobre si acaso tiene sexo la escritura. Una pregunta cuyas astillas siguen incrustadas a la matriz cultural para exponer -a la luz de una crítica con marcado carácter feminista, es decir, antipatriarcal, anticolonial, anticlasista, antirracista y antiteoheteronormativa desde mi perspectiva y posición-, cómo se distribuyen las parcelas de representación en la hegemonía discursiva que ha universalizado -y sigue universalizando- lo masculino/asociado a los varones. Para profundizar en la contingencia de este nudo para la sabiduría

Dice Adrienne Rich: "Una crítica radical a la literatura de arranque feminista tomaría el trabajo primeramente como una clave de cómo vivimos, de cómo hemos vivido, de cómo nos han educado a imaginarnos a nosotras mismas, de cómo nuestro lenguaje nos ha atrapado tanto como nos ha liberado, de cómo el acto mismo de nombrar ha sido hasta ahora una prerrogativa masculina y de cómo podemos empezar a ver y a nombrar y, por lo tanto, a vivir de nuevo" (47).

4 Sin considerar -al quedarnos en la herramienta del género solamente- otros ejes fundamentales en el proceso de subjetivación como lo son la raza, posición y origen de clase, el colonialismo, la razón teoheteropatriarcal, entre otras.

Domicilio literario administrado por la autoridad patriarcal que rige el campo cultural, literario. 
feminista, basta con ir a lo expuesto por Diamela Eltit a propósito del Premio Internacional Carlos Fuentes que le fue otorgado en abril de 2021:

Pienso que es necesario desbiologizar la escritura, pensar en producciones literarias, no genitalizarlas con las biologías hombre-mujer y desde allí a las categorías culturales, siempre binarias, de masculino-femenino, que como todo binarismo porta asimetrías. Mi idea es democratizar el espacio de la letra y romper, así, dominaciones culturales. Ya he dicho que en relación a la escritura no basta ser mujer, pero tampoco basta ser hombre (párr. 6).

Con el desafío de desbiologizar la literatura, entonces, estas notas se inmiscuyen en la institucionalidad literaria del siglo XX para dar cuenta de los procesos de inclusión y exclusión que marcan la irrupción e instalación de La brecha, de Mercedes Valdivieso, en la escena literaria de los sesenta, siendo esta una dominada por parámetros reduccionistas que privilegian la posición y presencia de los varones en el campo cultural.

"NunCA NADA TUVO NADIE SINO SU VOZ, EL CUERPO DE VOZ QUE HA SIDO SUYO"

La brecha está escrita en primera persona. En términos estructurales, el relato sigue un modelo convencional en la configuración de la historia, con inicio, nudo y desenlace, aunque el inicio del relato propiamente tal se desplaza por un "asomarse al tiempo como un túnel" (Valdivieso, La brecha 15), que enseguida introduce a las lectoras al conflicto central de la narración -y de la personaje protagonista, móvil de su acción-: "Antes de los veinticinco años debía adquirir un hombre -sine qua non- que velara por mí, me vistiera, fuera ambicioso y del que se esperara, al cabo de cierto tiempo, una buena posición: la mejor posible" (Valdivieso, La brecha 13). Las imposiciones de género de inmediato se vuelven parte fundamental de la evolución de la personaje que anhela la emancipación, como propone Lucía Guerra en su artículo sobre la misma novela7. "ME CASE como todo el mundo se casa" (ibid.), aunque todo el mundo, aquí, no es de cualquiera,

(Santa Cruz 11).

"La brecha (1961) de Mercedes Valdivieso representa una abrupta ruptura en esta tradición femenina de la novela chilena. Escrita en una época en la cual la mujer chilena había logrado el derecho a voto y el acceso más amplio a la educación, la autora, con plena conciencia de las contradicciones de su sociedad, inquiere en su circunstancia histórica y rechaza el solipsismo enajenante presente en la creación femenina anterior" (Guerra 6). 
sino "[e]se mundo de las horas de almuerzo, del dedo en alto, guardián de la castidad de las niñas" (ibid. $)^{8}$.

De esta forma, el sentido inicial del libro -el de la emancipación de la protagonista- está profundamente conectado a las ficciones de género que son producto de un orden patriarcal que lo domina y rige todo. En relación con esto, el libro (re)produce lo que se podría designar como un trayecto hacia la autoconciencia feminista que funciona, en el relato, del mismo modo en que lo hace en la teoría y práctica feminista, como un catalizador de sentidos para la creación literaria:

Según la crítica de arte Laura Cottingham, el "despertar de la conciencia" se convirtió en el primer método utilizado como catalizador para la creación del arte feminista de los setenta. Los grupos de autoconciencia permitieron, según Judy Chicago, "transformar nuestras circunstancias en nuestra temática, en vez de preguntarnos ¿quién soy?', nos preguntamos '¿quiénes somos?’”. Las artistas participantes en los grupos de autoconciencia organizados en los años setenta van descubriendo, al discutir sus propias vivencias, que lo que consideraban problemas personales o acontecimientos debidos al azar se encontraban generalizados entre todas las mujeres. Las consecuencias, como veremos a continuación, serán el desarrollo de la solidaridad, el activismo político y la multiplicación de redes $\mathrm{y}$ organizaciones que dotaron a las mujeres de espacios propios para la reflexión y la acción (Carro Fernández 122-123).

Se trata de una parcela colectiva de representación en la creación artística del periodo como parte de las propuestas, agendas y programas del/los activismos feministas de los años setenta ${ }^{9}$, para así pensar ya no en una

8 Es decir, un mundo que está definido por mucho más que las herramientas de sujeción del género, donde la posición de clase, por ejemplo, pasa a ser fundamental al momento de situar a la protagonista de la novela en la sociedad que traza el relato.

$9 \quad$ Si bien La brecha es una publicación de 1961, es decir, antecede por dos décadas a la época en que Carro Ferández sitúa su análisis, el uso de esta perspectiva sirve para ejemplificar y delinear uno de los ejes sustanciales de revisión de este estudio, como lo es el llamado arte feminista que la filósofa identifica en la década de los setenta en Estados Unidos. No obstante, me parece que se puede aprovechar el potencial nominativo de la categoría, que nos permite ampliar el alcance del término para aplicarlo y usarlo en función del signo que designa un fenómeno que si bien, antes de los setenta anglosajones no había sido designado como tal en nuestra Latinoamérica, definitivamente podemos encontrar distintas manifestaciones con 
mujer ni en todas ellas, sino en nosotras como un todo; para ir un paso más adelante del yo, neutralizar la coherencia de la sujeta protagonista de la acción feminista e introducir, definitivamente, la posibilidad de su colectivización, no borrando, sino exponiendo, mostrando, haciendo visible en ese tejido las incoherencias de los cuerpos, de sus experiencias, siempre diferentes unas de otras, en activo movimiento -como los mismos cuerpos-: un modo de legitimar sus escrituras en el campo, siendo un nosotras, una posibilidad de empuje a la acción desde la colectivización de la demanda en una narrativa que nos convoca, reúne.

Si volvemos a la advertencia al inicio de la novela de Valdivieso podemos agregar cómo, en esas tres líneas apenas, ya está sugerido lo que podemos leer como una estrategia de enunciación que colectiviza y amplía la voz enunciativa del relato: "El personaje de esta novela no tiene nombre, pero podría ser el de cualquier mujer de nuestra generación" (Valdivieso, La brecha 7. Las cursivas son mías). No tener nombre como sinónimo de escribir cualquier nombre encima, de poder representar a cualquiera a pesar de que la categoría mujer, el signo abierto, aparece siempre demarcado porque se refiere a las mujeres, sí, pero de "nuestra", es decir, "su generación"10: una colectivización pactada con la realidad del contexto en que la misma autora experimenta la sujeción de su identidad y proceso identitario.

La realidad del texto se cruza con la del contexto y este último pasa a ser un aspecto sumamente relevante al entrar a leer los discursos y sentidos inscritos en el mensaje de la novela de Valdivieso, sobre todo cuando se intenta hacer una lectura sobre los discursos, estéticas y feminismos articulados en el relato.

características del denominado arte feminista antes, por ejemplo, en La brecha, por ejemplo, en Latinoamérica, por ejemplo, en Chile.

10 Como he sugerido antes, la posición de clase de la protagonista también se consolida como rasgo característico para constituir o delimitar su identidad. Pienso que una crítica de arranque feminista, hoy, debe ser tan antipatriarcal como antirracista, anticolonialista, anticlasista y estar en contra de una razón teoheteronormativa. En este sentido, si bien mis apuntes no se detienen especialmente en la posición de clase de la protagonista del relato, sino en algunas de las ideas en la aparición e instalación de La brecha como dispositivo literario -libro-en el campo cultural de mediados del siglo XX, me parece fundamental señalar que la posición de clase de la protagonista es sustancial al momento de bosquejar la acción posible de la misma, pues su procedencia burguesa - de una burguesía en descenso, pero burguesía al findetermina tanto las aspiraciones de la protagonista como sus líneas de acción en el conflicto -las posibilidades mismas de actuar, pues la clase actúa, sabemos, como condicionante de la acción de cara a una sociedad/sistema de clases-. 
Involucrar la coyuntura social para convocar, reunir y articular movimientos o agrupaciones de mujeres, así como usar la literatura como un dispositivo que cataliza ideas políticas y el pensamiento siempre en movimiento del discurso feminista del periodo, son también modos de erguir una estrategia política de articulación feminista (la de la autoconciencia) para enunciar desde adentro hacia afuera: lanzar un yo disuelto al mundo y con ese yo, todas ellas, todas las que entren en ese mensaje de emancipación que el relato y su protagonista "cualquiera" construyen.

Convocar se usa aquí como mecanismo de introducción al despertar feminista, pues la novela, al presentar una historia sobre la subversión o transgresión de parte de las normas y asignaciones de género que el sistema produce y reproduce en la realidad material de las lectoras - del Chile de los sesenta-, puede ser leída como una acción política feminista que subvierte de manera evidente esa norma en su construcción de sentidos, al producir un dispositivo que los porta y difunde: un arte feminista ${ }^{11}$.

\section{DEL SILENCIO AL ENUNCIADO: "TENGO GANAS DE SER NUESTROS NOMBRES"12}

El presente de la novela es el mismo en el que la teórica y activista Julieta Kirkwood comienza a registrar la historia de las articulaciones de mujeres y feministas en Chile en su Ser política en Chile de 1982. Me refiero al periodo designado como el del silencio femenino/feminista, uno de los productos, como dice Kirkwood, de la meta de liberación global impulsada por la izquierda del periodo ("Tengo" 115) 13 .

11 Si bien me parece que este tipo de categorías, como todas, cuentan con el peligro de reducir el espacio en el que se instalan, así como lo que designan, también pienso que hacer uso de la noción misma es emplearla a raíz de su potencial político, de visibilización del objeto, como proponen Andrea Kottow y Ana Traverso en su Escribir \& tachar (2020) a propósito de la noción de escritura de mujeres.

12 (Kirkwood, "Tengo" 115). La cita alude al título del texto que fue publicado originalmente el 11 de septiembre de 1982 como editorial de la revista Furia $N^{o} 4$ y lo encuentran online en memoriachilena.gob.cl.

13 Para una lectura más profunda del fenómeno de la liberación global como nudo feminista del periodo sugiero revisar el capítulo IV, "La liberación global”, de Ser política en Chile. 
A la luz del estudio de Susana Carro Fernández, mencionado antes para introducir el concepto de "arte feminista", vale preguntarnos cuál era el programa feminista al que se podía aspirar desde el silencio como signo para leer la acción y presencia feminista en el contexto en el que está instalada la autora y su libro: ¿bajo qué condiciones se decide escribir y publicar una novela como La brecha y cuál va a ser el modo en que la autora va a describir ${ }^{14}$ su propia escritura? En definitiva, enmarcar el estudio en su propio contexto para situar la lectura en un punto de vista crítico respecto al uso de estrategias y metodologías usadas para describir al objeto de estudio, porque son herramientas que no están contextualizadas en la realidad del objeto que se estudia, sino situadas y, por lo mismo, conceptualizadas desde una realidad anglosajona, con una comprensión de la historia del movimiento que lo segmenta en periodos, olas, momentos, como es la de los feminismos a los que se refiere Carro Fernández en su artículo.

Entonces, si bien no podemos fiarnos de la compatibilidad entre las ideas y los hallazgos presentados en estas notas con los de Carro Fernández en su estudio, sí podemos hacer uso de conceptos para visibilizar algunas intersecciones entre estrategias estéticas y políticas feministas presentes en la construcción de la novela, como la autoconciencia feminista mencionada antes, la cual funciona como un propósito articulador del movimiento feminista del periodo. De cierta manera, esta última también responde a la pregunta de Richard, pues "los criterios para distinguir arte de artesanía derivan de quién ha realizado la obra que se está juzgando" (Carro Fernández 144-145), ya que la "genialidad" del genio es un rasgo que caracteriza al creador -y no a la creadora-, o sea, es un rasgo determinante al momento de leer el ingreso e instalación de la literatura escrita por mujeres en el campo literario y cultural.

Lo anterior me parece interesante si vamos a perspectivas como la de la crítica e historiadora de arte estadounidense Linda Nochlin ${ }^{15}$ sobre el lugar a/signado a las mujeres en el arte. En su ensayo de 1971 “¿Por qué no ha

14 Recordemos la entrevista realizada por Lucía Guerra en 1981, en la que Valdivieso dice: "Cuando escribí La brecha yo estaba muy consciente que a la mujer se le había asignado un lenguaje, el lenguaje que el amo le supone al ser dominado. Por esta razón me propuse utilizar un lenguaje femenino directo, despojado de toda mentira y todo subterfugio" (cit. en Guerra 9).

15 Además de la de Nochlin, que es la perspectiva que trabajo en profundidad en estas notas, me parece fundamental la perspectiva actual sobre el problema del genio en la literatura, en la creación, como la de Julieta Marchant en su clase magistral "Contra el cliché" que 
habido grandes mujeres artistas?" Nochlin advierte un problema medular en el criterio de grandeza para describir el genio del artista, pues este no es más que el resultado de los mecanismos de diferenciación y exclusión de una institucionalidad literaria evidentemente teoheteropatriarcal, racista, clasista y colonialista, que universalizó lo masculino, occidental y blanco, estableciendo los parámetros de la grandeza en relación con una razón que responde a un sistema que produce y reproduce esos parámetros:
“¡Por qué nunca han existido grandes artistas mujeres?” La pregunta clama reprochando desde el fondo de la mayoría de las discusiones en torno a la llamada cuestión de las mujeres. Sin embargo, al igual que tantas otras cuestiones relacionadas con la "controversia" feminista, ésta falsifica la naturaleza del asunto, al tiempo que, insidiosamente, ofrece su propia respuesta: "No han existido grandes artistas mujeres porque las mujeres son incapaces de llegar a la grandeza" (Nochlin 26).

El mito de la grandeza en el arte, del arte mismo ${ }^{16}$, visto desde aquí, apela a introducir la existencia de un estilo asociado a las mujeres - mal llamado "femenino"-que sea distintivo y reconocible, producto de las características, situación y experiencia de las mujeres que siempre es particularizada, mínima y otra a la luz de la experiencia del universal masculino que es el hombre: otra vez la mujer como pionera de la historia, otra vez el revés disfrazado de necesidad aunque sea imposición, obligación para consagrar la dominación masculina, la de empujarnos a un espacio de subversión obligatoria. Además el arte, nos recuerda Nochlin, no es algo que esté "sobre" sino "en" lo humano:

El problema [de esencializar la producción artística de mujeres] reside, no tanto en algunos conceptos feministas de lo que es la femineidad, sino en la falsa interpretación de lo que es arte, compartida con el público en general; en la ingenua noción de que el arte es la expresión directa y personal de la experiencia emocional individual, una traducción de la vida propia en términos visuales. El arte casi nunca es eso y el gran

tuvo lugar en el marco del encuentro \#PoesíaYa, actividad coordinada por el Centro Cultural Kirchner, este año (2021).

16 Dice Ernst Gombrich, en su prefacio a La historia del arte de 1995: "No existe, realmente, el Arte. Tan sólo hay artistas [...] mientras advirtamos que el Arte, escrita la palabra con A mayúscula, no existe, pues el Arte con A mayúscula tiene por esencia que ser un fantasma y un ídolo" (21). 
arte nunca lo es. Hacer arte supone un lenguaje de formas consistente, más o menos dependiente de o libre de (dadas las convenciones temporalmente definidas) una estructura o sistemas de notación que tiene que ser aprendido o discernido ya sea mediante la instrucción, el noviciado o un largo periodo de experimentación individual. El lenguaje del arte, en el ámbito material, se engendra en pintura y en línea sobre lienzo o papel, en piedra, arcilla, plástico o metal. No se trata ni de un melodrama ni de un susurro confidencial (28).

Otra propuesta a considerar de Nochlin: quizás lo único que agrupa al arte producido por mujeres en alguna noción genérica es que las mujeres a las que agrupa tuvieron un acceso, todas ellas, a una institucionalidad a la que otros grupos no ${ }^{17}$. Ese espacio -el de la institucionalidad literaria, teoheteopatriarcal, racista, clasista y colonialista- será el que percibirá el ingreso de las escritoras con sus escrituras "de mujeres" como un peligro por la disputa de las parcelas de representación que implicó la instalación de las escritoras en el campo: se levantan las armas del crítico, se limita el lugar de las escritoras en esa institucionalidad literaria. Escritoras como Mercedes Valdivieso son vigiladas, monitoreadas, registradas o leídas en su ingreso e instalación al campo como producto de las estrategias de sujeción y distribución de las parcelas de representación en algo tan central como lo es el discurso literario. Así, los críticos que dijeron "literatura de mujeres" en realidad dispusieron de un lugar para coartar su pertenencia al campo, aquel no-lugar dentro del lugar, creado para marcar la escritura producida por mujeres en separación o como un anexo a la escritura producida por varones que es, como sabemos, esa literatura "a secas": vara y medida del punto de vista universal en las literaturas.

Con todo, podemos decir que el arte feminista al que nos referimos se definió en la acción y programa feministas, como parte de las estrategias que recuperan los territorios históricamente negados a las mujeres, relacionado con las ya mencionadas parcelas de representación de las cuales son excluidos los cuerpos virtuales y materiales de las mujeres y otras identidades en una posición desigual respecto al sistema dominante:

17 Cuestión que, por lo demás, permite exponer la interseccionalidad presente en los feminismos. 
Como afirma Estrella de Diego, sólo a partir de los años 60 surge y prolifera "un tipo de arte conscientemente subversivo que recuperará los territorios negados históricamente y las parcelas incómodas de la representación" [...]. Arte feminista será la denominación genérica de tales propuestas [...] activismo feminista y arte feminista son inseparables a principios de los años setenta, de ahí que si intentamos comprender este último será necesario remitir no solo a las principales conceptualizaciones de la teoría feminista del momento, sino también a la historia de su organización (Carro Fernández 118).

El contexto nacional, al revés de la situación anglosajona descrita sobre todo por el pensamiento de Carro Fernández, será el del ya mencionado silencio feminista, cuya denominación responde a una subordinación de los problemas de las mujeres en función de la liberación global del periodo, la cual "se ha planteado en política como un saber último, en el sentido de mostrarse como una teoría ya hecha, acabada, y que debe ser llevada a la praxis por los sectores más conscientes de la sociedad: el proletariado y sus vanguardias políticas" (Kirkwood, Ser política en Chile 138).

Sin embargo, la misma Julieta Kirkwood agrega que este silencio no significa una completa y total inexistencia de los problemas de las mujeres de lo social, a pesar de lo que el relato oficial ${ }^{18}$ dirá, pues

Se la estudia, moderadamente, pero desde una perspectiva en que el verdadero protagonista de ese análisis no es precisamente la mujer en sí, sino que se la toma como otro elemento -posible o no- de ser incorporado a un proceso de liberación global, ya en marcha, ya elaborado, al cual había de sumarse posteriormente, y cuya forma de inserción dependería fundamentalmente de su adscripción o pertenencia a clases sociales y a la eventualidad de poseer una adecuada conciencia de clase (ibid.).

Así, el silencio se constituye como un elemento central para la elaboración de estas notas, pues es leído como uno de los efectos de las fuerzas neutralizadoras de la historia de las que escribe Pierre Bourdieu:

[una serie de] mecanismos históricos responsables de la deshistorización

18 Dice Bourdieu en La dominación masculina: "Recordar que lo que, en la historia, aparece como eterno solo es el producto de un trabajo de eternización que incumbe a unas instituciones (interconectadas) tales como la Familia, la Iglesia, el Estado, la Escuela, así como, en otro orden, el deporte y el periodismo" (8). 
y de la eternización relativas de las estructuras de la división sexual y de los principios de división correspondientes [...] Recordar que lo que, en la historia, aparece como eterno solo es el producto de un trabajo de eternización que incumbe a unas instituciones (interconectadas) tales como la Familia, la Iglesia, el Estado, la Escuela, así como, en otro orden, el deporte y el periodismo [o la literatura] (8).

En la medida en que leamos estos problemas desde un lugar similar al que propone Bourdieu y nos preguntemos, en efecto, por las fuerzas neutralizadoras de la historia, pienso, podremos reinsertar el curso de la misma y así devolver a las mujeres la acción histórica que ese pensamiento reduccionista, "biologizante" de la literatura, parafraseando a Eltit, toma como base ontológica -la biologización de la literatura- para la exclusión y diferenciación de las mujeres de la institucionalidad literaria, de la literatura "a secas". Reinsertar el curso de la historia, así, no solo para devolver la acción histórica a las políticas feministas, ir más allá de las olas y de la lógica del progreso para pensar en el curso del trayecto de los feminismos, sino también o sobre todo, para legitimar el curso de su acción, política, como parte y no anexo, de la historia (una, oficial), que siempre está afectando, trastocándolo, todo.

\section{"UN LENGUAJE FEMENINO DIRECTO, DESPOJADO DE TODA MENTIRA Y TODO SUBTERFUGIO"19}

A pesar de la visión crítica enunciada antes, a partir de la cual se podría inferir una irrupción con una respuesta bulliciosamente negativa de La brecha en general, la novela está marcada por una crítica que celebra, aparentemente, su aparición:

Una de las más extraordinarias manifestaciones de esa entrada triunfal de la mujer en la literatura, entrada ya no discutida y tan espontánea que la primera obra de esta nueva escritora diríase una obra de madurez y el estilo de esta principiante podrían envidiarlo por su sencillez, su elegancia y su soltura, viejos autores que han hecho del arte el trabajo de su vida (Alone s/p). 
Y como Díaz Arrieta, Fernando Alegría en el prólogo a la primera edición de 1961, dice:

Nos preguntamos si la forma que ha escogido para narrar su historia constituye, en realidad, un estilo. Parece difícil creerlo. No se da una conjunción tan perfecta de tema y lenguaje sin la ventaja de un lento aprendizaje literario. La frase corta, directa, de explosiva carga sentimental que, sin embargo, nunca estalla, dejándose sentir tan solo y quemando desde adentro a través de un exterior limpio y nítido, es la frase que corresponde a un desahogo de dramática urgencia. No hay aquí lugar para la retórica (cit. en Valdivieso, La brecha 10).

Los dos comentarios críticos anteriores ejemplifican el repetido gesto de exclusión ${ }^{20}$, empleado por el crítico literario del siglo XX, para mantener o resguardar su hegemonía discursiva en la institucionalidad literaria, que se configura en relación con un orden que produce y reproduce la dominación masculina, al erigir una estrategia de reconocimiento y validación crítica, de aparente apertura, cuando, en realidad, son las herramientas del crítico -la artillería de la exclusión- las que están trabajando a toda máquina para leer y signar esas escrituras y producciones de las mujeres. Otra forma de coartar los aportes, ingresos y presencias de las mujeres en calidad de autoras al campo -cualquiera sea-. Aquí me refiero al gesto de designar el lugar en el que opera la escritura de Mercedes Valdivieso en la previamente bosquejada escritura o literatura de mujeres, la cual, en esa institucionalidad literaria en la que se instala, es asociada a una literatura menor, subordinada a la producida por varones -o sea, la mayor, la general, la literatura de los grandes relatos-.

Por un lado, Hernán Díaz Arrieta realiza una lectura del ingreso triunfal de la mujer en la literatura con Mercedes Valdivieso, dejando en el olvido medio siglo de historia literaria, si situamos la profesionalización del oficio literario para las mujeres a fines del siglo XIX e inicios del XX, como lo hace Beatriz Sarlo en su Modernidad periférica (1988).

Puede que tenga razón, el crítico, si vamos al segundo comentario, el de Alegría, quien al preguntarse por la forma del relato de Valdivieso, por sus estrategias de enunciación, alude a un estilo inventado -y que quizás ni 
siquiera puede ser señalado como estilo, sin espacio para la retórica, no lo olvidemos-y hace evidente una lectura que nos arroja a la pregunta de Nelly Richard nuevamente. Una y otra vez nos preguntamos si acaso las palabras, el lenguaje, todo este continente, la violencia que se nos impuso en la lengua y nos dejó heridas abiertas, nos pertenece o, de ser así-que nos pertenezca-, entonces a quiénes.

Cuando digo que puede que Díaz Arrieta tenga razón, me refiero específicamente a su comentario sobre el ingreso triunfal de la mujer a la literatura, pues no será hasta la década de los ochenta que las mujeres ingresen ${ }^{21}$, si acaso podemos ser tajantes, a las literaturas, lo cual podría, sin dudas, ser parte del efecto de la colectivización de la voz en el ya comentado gesto de desplazar el yo para decir un nosotras ${ }^{22}$.

Como otras escritoras de la "generación inventada"23, Mercedes Valdivieso pasó a formar parte de la capa de escritoras cuyas autorías estarían sujetas a

21 "Pareciera que recién en los años ochenta, la mujer escritora chilena trasciende su aislamiento individual. Pareciera que por primera vez podría hablarse de escritura de mujeres, así, en plural. Pareciera que en sus diferencias, por primera vez esta escritura de mujeres tiene rasgos que la definen como tal a partir de escritos heterogéneos con características que innovan, se repiten, sugieren, explicitan" (Bianchi 126).

22 Con todo lo que implica escribir un nosotras a pesar del yo, a pesar de la heterogeneidad de las sujetas que se agrupan en ese nosotras, a pesar de que sea utilizado como una estrategia de visibilización del problema en la agrupación de las mujeres, en el colectivo, de visibilización masiva a un problema estructural que toca no a uno, sino a todos los cuerpos que convoca esa colectividad, por lo tanto, no puedo dejar de mencionar y defender esa heterogeneidad presente en ese "nosotras".

23 Así designa Raquel Olea a esa generación de "escritoras que no fueron incorporadas en la antología de Lafourcade (Marta Jara, Mercedes Valdivieso, Elisa Serrana, Elena Aldunate, Matilde Ladrón de Guevara), aunque cumplieran con las características señaladas por el antologador, han padecido un olvido que recientemente empieza a ser abandonado, por el hecho de ser leídas como un corpus de textos que se ha comenzado a denominar como Escritoras de la Generación del 50. Sus obras fueron publicadas por Zig-Zag en la década de 1960, y aún se encuentran en librerías de viejos en la calle San Diego de Santiago. Elisa Serrana ha sido reeditada por Editorial Andrés Bello en 2002 y un volumen titulado Obras selectas recupera la totalidad de su narrativa; Marta Jara ha sido publicada por Lom Ediciones; Mercedes Valdivieso por Editorial Cuarto Propio, y su libro La brecha ha sido calificado como la primera novela feminista por la crítica de los años noventa. Mérito o arbitrariedad del inventor, el problema invita a repensar, no solo el invento, sino la parcialidad de las lecturas relativas a las significaciones de los textos. Sin embargo, lecturas actuales proponen reconsiderar a estas autoras y pensar su escritura junto con quienes fueron antologadas, no para ejercer una demanda de inclusión en el canon de Lafourcade, sino para constituir un 
una categoría tan compleja y peligrosa como la de "literatura de mujeres", comúnmente asociada al registro confesional de la experiencia íntima o la configuración de un relato a/signado en las herramientas de sujeción de la identidad, para reducir los múltiples significados de esas escrituras, sobre todo, en relación con su contexto, su estética, su literatura y cultura:

Estas mujeres [la generación de escritoras a la que Valdivieso pertenece] llegan a nuestra literatura con un mensaje que en su descarnada franqueza, en su sensualismo abierto y provocativo, no tiene paralelo sino en la obra de las grandes poetisas de principios de siglo: de la Mistral, la Agustini y la Storni. Sus novelas poseen la fuerza del testimonio verídico y la fina elaboración del texto poético (Alegría cit. en Valdivieso 12).

El nudo reduccionista que opera en la noción "escritura de mujeres" nos hace volver, de una vez y por todas, a la pregunta de Richard, ahora considerando aspectos de la publicación, lectura, recepción y difusión e instalación de un acontecimiento literario como La brecha.

En efecto, la escritura de mujeres es una noción que si no se usa aprovechando su potencial estratégico -el de agrupar a las mujeres en una especie de corpus binario y excluyente, biologizante, solo a partir del mito mujer anclado a la práctica material de la escritura ${ }^{24}$ - peligra de ser utilizada como categoría reduccionista que fije la escritura a un género y un cuerpo -y no a los cuerpos que producen esas escrituras, cuyas características comunes son, de hecho, su lugar de subordinación en relación con la opresión de la dominación patriarcal-.

corpus que legítimamente lea lo que de manera crítica no pudo considerarse, y así repensar el aporte de una literatura de anticipo con el fin de remover y combatir 'algo del orden social e histórico', inscrito en los signos de una cultura masculina que no fue explícitamente elaborado por sus pares contemporáneos y que tuvo especiales resonancias contextuales" (103-104).

$24 \quad$ "Hablar de 'escritura femenina' supone volver a afirmar que las mujeres no pertenecen a la historia y que la escritura no es una producción material. La (nueva) feminidad, la escritura femenina, el elogio de la diferencia, suponen un retroceso respecto a una corriente política comprometida desde hace mucho en el cuestionamiento de las categorías de sexo, esos dos grandes ejes de categorización para la filosofía y las ciencias humanas. Como ocurre siempre que algo nuevo aparece, se interpreta inmediatamente y se lo convierte en su contrario. La escritura femenina es como las tareas del hogar y la cocina" (Wittig 85-86). 
Ir en contra de este peligro latente -el del reduccionismo, aún presente en nuestra escena literaria y la crítica que la recibe, consagra y designa-implica tomar esta estrategia, de hecho, como tal: haciendo uso del potencial político de la noción, cuyas fórmulas de visibilización potencian la reinserción del ya sugerido curso real de la historia, como lo proponen Andrea Kottow y Ana Traverso en Escribir \& tachar. Narrativas escritas por mujeres en Chile (1920-1970), publicado el pasado 2020 por Ediciones Overol:

Proponemos la escritura de mujeres como una plataforma estratégica de enunciación. Frente a la efectiva invisibilización de muchas autoras en la historia de la literatura y en sus procesos de canonización, podría pensarse la noción "escritura de mujeres" como estrategia visibilizadora. Es mantener una categoría por su potencial político, si por ello entendemos la conciencia y la posibilidad de cuestionar las categorías de poder imperantes. Existe una escritura de mujeres, entonces, porque no existe una escritura de hombres, pues esta ha asumido un carácter universal que consecuentemente ha marginado en importante medida a las mujeres de su historia (10).

Aprovechar la noción así, como una plataforma estratégica de enunciación, es aprovechar el potencial político de la categoría y promover, de una vez por todas, la agencia histórica política de las mujeres en la literatura y otras disciplinas, cualquiera de ellas. Una reinserción de la historia en los términos de Bourdieu.

A pesar de esto, sabemos, la escritura de mujeres no será el único mecanismo para situar las escrituras producidas por mujeres. De eso saben autoras como María Luisa Bombal o Marta Brunet, por nombrar a dos autoras reposicionadas y legitimadas hoy por una crítica con marcado carácter feminista.

Para dar con el problema de la reducción biográfica en la institucionalidad literaria del siglo $\mathrm{XX}$, basta que transitemos la historia del fracaso ${ }^{25}$ como

25 Basta que recordemos el sexismo en las notas que año a año se escriben sobre el Premio Nacional de Literatura en Chile y a la hora de otorgar el galardón, un recordatorio de las seis escritoras que lo han recibido a la fecha y, como siempre, el fracaso de las que debieron recibirlo, como Bombal, siempre Bombal, porque el suyo es un destino trágico más allá de haber escrito dos novelas, cinco cuentos, tres crónicas de poetas y dos traducciones/reescrituras al inglés. No haber obtenido el premio, el reconocimiento material, la hace merecedora de una trayectoria literaria anclada al fracaso a pesar del poder y la trascendencia de sus letras. 
lugar común de la experiencia de la mujer en la legitimación en el campo y la trayectoria pública del relato que hizo uso de las ficciones íntimas, reducción biográfica, de las escritoras para deslegitimar sus autorías, escrituras y proyectos intelectuales. Bombal, en el llamado lado "femenino" del binario, apuntalada por el fracaso literario de cara a la tragedia de su vida -como la designa hasta hoy una crítica sexista, donde el éxito, la excelencia, se mide a la par de lo privado en la vida de las mujeres, de sus experiencias vitales y no escriturales- es considerada la voz más femenina de todas ${ }^{26}$ por ese crítico literario que representa la institucionalidad literaria del momento en que se publica su obra. Brunet, en la otra vereda, es expuesta a una masculinización ${ }^{27}$ de su autoría para argumentar la genialidad de su pluma: dos técnicas más de las estrategias de sujeción del ingreso e instalación de las escritoras en el campo: la feminización y la masculinización ${ }^{28}$.

En el caso de Mercedes Valdivieso y La brecha ocurre una cuestión interesante ${ }^{29}$, ya que el perfil de la intelectual permite una fricción entre una y otra posibilidad, pues, sigue Alegría:

Mercedes Valdivieso deja en su novela hombres y cosas en que descubrió una forma de vivir, una forma que rechaza y de la cual se aleja al cerrar un periodo de su existencia. Se vislumbra en ella, entonces,

26 El 11 de mayo de 1980, en el suplemento cultural de El Mercurio, Ignacio Valente, despojándose de su connotación intelectual para firmar como José Miguel Ibáñez Langlois, a propósito de la muerte de la escritora y el nacional que le fue negado en vida, la designa como "la voz más femenina de la literatura nacional": "Ha muerto María Luisa Bombal. Ha muerto sin el Premio Nacional de Literatura. Igual que Juan Emar. Las dos más altas cumbres de la narrativa chilena de este siglo han compartido un doloroso destino: el pago de Chile. A María Luisa Bombal no se le mezquinará lo único que este país asegura a sus escritores: las honras póstumas, los discursos fúnebres, los actos conmemorativos. Se la llamará, y con razón, la voz más femenina de la literatura nacional" (cit. en Gligo 171).

$27 \quad$ A estas alturas, son conocidos los comentarios de críticos que masculinizaron a la escritora por la nombrada calidad de su genio. Carlos Silva Vildósola, por ejemplo, aseguraba que "este [Marta Brunet] es un escritor; no una escritora, aunque sea una dama" (cit. en Amaro 26).

28 Para profundizar en esto sugiero el artículo de Darcie Doll "Escritura/Literatura de mujeres: crítica feminista, canon y genealogías" (2002), en el que desenmaraña de modo profundo, directo y agudo estas estrategias de sujeción de las escritoras y sus proyectos literarios en el campo -reducción biográfica, feminización y masculinización-.

$29 \quad \mathrm{Al}$ menos para el binarismo de género que todo lo piensa partido a la mitad, con una división posible, clara, marcada. 
la voluntad de descubrir su propio estilo de vida y de forjarlo con libertad, con vigor, con valentía. De ahí que su historia no tenga fin. Seguirá moviéndose entre seres reales y sombras de seres, buscando su camino (cit. en Valdivieso, La brecha 12).

Valdivieso pertenece, también, a la generación de escritoras que, en efecto, ingresan al campo como intrusas y por lo mismo, como rarezas, fisuras del orden que produce y reproduce la dominación patriarcal. Así como Brunet y Bombal, es parte de un grupo de escritoras que cruzaron con éxito las cercas de la ciudad letrada, pero sin olvidar que esta se trata de una ciudad no solo patriarcal, sino también racista, clasista y teoheteropatriarcal, por lo que la parcela de representación una vez adentro, se va a disputar desde distintos aspectos y posiciones.

En el fondo, no estoy más que repitiendo e incorporando la lectura que hace Ana Traverso -y así como ella, Darcie Doll, Kemy Oyarzún, Soledad Bianchi, entre otras críticas, docentes e investigadoras- a la historia de la crítica literaria del siglo XX de cara a la escritura producida por mujeres. Lecturas que se dirigen a las tácticas institucionales que afianzan el sistema de exclusión al que me refiero y que Traverso incorpora, desde la perspectiva de Kemy Oyarzún, como una escritura afrancesada/femenizada de mediados del siglo XX (72), en oposición a una escritura criollista/masculinizada, concepto o descripción que se incorpora a la artillería del crítico literario del periodo para introducir otra estrategia de sujeción de la literatura en ese juego de inclusiones y exclusiones a las escrituras producidas por mujeres.

La maniobra paradojal de la inclusión y exclusión en la instalación de las escrituras producidas por mujeres en la institucionalidad literaria del siglo XX es evidente. Al mismo tiempo que se negocia la entrada de la(s) escritora(s) a la escena se transan una serie de normas del entorno social que pactan un acuerdo de coherencia de roles e imposiciones de género, raza, clase y sexualidad en el paso de la aparición a la instalación en la institucionalidad literaria del periodo. Siguiendo a Natalia Cisterna, esto es parte de una

obstinación crítica que solo puede ser entendida en el marco de los mismos prejuicios con los que se codificó y ha codificado la literatura de mujeres. En efecto, para un espacio cultural y claramente androcéntrico, es mucho más comprensible entender la obra de una escritora vislumbrando un proceso de transformación artística, que constituyente en sí misma una transformación (118). 
Es decir, las negociaciones y transas de Mercedes Valdivieso, así como la de otras escritoras del periodo, operan ante la posibilidad, el peligro latente, de una "negación total de sus existencias como escritoras" (ibid.).

Precisamente, Mercedes Valdivieso y La brecha desafían la hegemonía discursiva que coarta el ingreso e instalación de las escritoras el siglo XX en la institucionalidad literaria del periodo. La historia del relato, la escritura, el texto mismo, comunican una disputa por la hegemonía discursiva, a contrapelo del lenguaje y a pesar de que las condiciones materiales de producción, publicación, difusión e instalación de la novela debut de Valdivieso promueven un discurso que apela al éxito de la entrada de esta escritora al panorama literario de mediados del siglo XX. Por otra parte, la definición de la agenda feminista del contexto - cuyo programa alentó una autoconciencia feminista capaz de reactivar ese movimiento feminista que Julieta Kirkwood leyó apaciguado en las dos décadas anteriores a la dictadura, específicamente tras la obtención del voto universal en 1949- se construye como una premisa fundamental en las prácticas y políticas feministas del periodo, lo que nos permite pensar la vigencia de La brecha como una de las primeras novelas feministas latinoamericanas ${ }^{30}$.

Vista desde aquí, La brecha convoca la colectivización y materialización del discurso de la experiencia de esos cuerpos que reconocen su subordinación y disidencia en la protagonista cualquiera, pero mujer, porque ellas -las lectoras-, al igual que la protagonista, han experimentado la dominación masculina -aunque como tensioné, con características de clase, raza y sexualidad que sujetan y modelan la identidad, por lo tanto, cualquier mujer en realidad no es cualquier mujer-. El arte siempre está sujeto a las ideologías, parece recordarnos Valdivieso, para enunciar no una, sino todas esas brechas antiguas, nuevas, manifiestas de las desigualdades que siguen afectando la experiencia vital, simbólica y política de las mujeres hoy, a sesenta años de la publicación del libro. 


\section{BIBLIOGRAFÍA}

Alone. "Reseña de La Brecha". El Mercurio, 1961.

Amaro, Lorena. "En un país de silencio: Narrativa de Marta Brunet". Marta Brunet. Obra Narrativa. Cuentos-Tomo II. Edición crítica de Natalia Cisterna, Santiago, Ediciones Universidad Alberto Hurtado, 2017, pp. 15-82.

Bianchi, Soledad. "Lectura de Mujeres". Ver desde la Mujer. Olga Grau (ed.), Santiago, Ediciones La Morada y Cuarto Propio, 1990, pp. 125-141.

"La exclusión como repetido gesto". Cyber Humanitatis 21 (web), consultado el

21 de noviembre de 2021, disponible en:

https://revistaderecho.uchile.cl/index.php/RCH/article/view/5567

Bourdieu, Pierre. La dominación masculina. Madrid, Anagrama, 2001.

CARro Fernández, SusAna. "De la ética a la estética feminista: Intersecciones contemporáneas entre práctica artística y teoría feminista”. Cuadernos Kóre. Revista de historia y pensamiento de género 6, 2012, pp. 115-147.

Cisterna, NATALIA. "La definición de las trayectorias literarias en dos escritoras chilenas modernas: María Flora Yáñez y Marta Brunet”. Revista Chilena de Literatura 86 (2014): 101-120.

Eltit, Diamela. "Es necesario desbiologizar la escritura, pensar en producciones literarias, no genitalizarlas con las biologías hombre-mujer". La Tercera, entrevista con Pablo Retamal, 8 de abril de 2021, consultado el 21 de noviembre de 2021, disponible en: https:/www. latercera.com/la-tercera-pm/noticia/diamela-eltit-es-necesario-desbiologizar-la-escriturapensar-en-producciones-literarias-no-genitalizarlas-con-las-biologias-hombre-mujer/ RGNCIBHYM5EFVJV2AJGTORUD6Y/

Gligo, Agata. María Luisa. Santiago, Editorial Andrés Bello, 1985.

Guerra-Cuningham, Lucía. "Feminismo y subversión en La brecha de Mercedes Valdivieso". Literatura chilena, creación y crítica XXI, 1982, pp. 5-9.

Gombrich, ERnest. La historia del arte. Londres, Phaidon, 2011.

Kirkwood, Julieta. Ser politica en Chile. Santiago: Cuarto Propio, 1990.

"Tengo ganas de ser nuestros nombres". Tejiendo rebeldías. Julieta Kirkwood, edición de Patricia Crispi, Santiago, La morada, 1987, pp. 115-116.

Kottow, Andrea y Ana Traverso. Escribir \& tachar. Narrativas escritas por mujeres en Chile (1920-1970). Santiago, Overol, 2020.

Marchant, Julieta. “Contra el cliché - Por Julieta Marchant - Clase magistral - Poesía ya!”, YouTube, Centro Cultural Kirchner, disponible en:

https://www.youtube.com/watch?v=RYNMp9k6_Js\&t=9s\&ab_channel=CentroCulturalKirchner

Nochlin, Linda. “¿Por qué no han existido grandes mujeres artistas?”. Situar en la historia. Mujeres, arte y sociedad. Linda Nochlin, Madrid, Ediciones Akal, 2020. pp. 25-49.

Olea, Raquel. "Escritoras de la generación del cincuenta. Claves para una lectura política". Revista UNIVERSUM 25, 2010, pp. 101-116. 
Richard, Nelly. Masculino/Femenino: Prácticas de la diferencia y cultura democrática. Santiago, Francisco Zegers Editor, 1993.

Rich, AdRIENNE. "Cuando las muertas despertamos: escritura como re-visión". Sobre mentiras y secretos y silencios. Adrienne Rich, Barcelona, Icaria editorial, 1983.

Santa Cruz, Guadalupe. Esta parcela. Santiago, Alquimia Editorial, 2015.

Traverso, Ana. "Ser mujer y escribir en Chile: canon, crítica y concepciones de género". Anales de la Literatura Chilena 20, 2014, pp. 67-69.

TríAs, FernAndA. "Cátedra Abierta en homenaje a Roberto Bolaño - Fernanda Trías, YouTube". YouTube, Facultad de Comunicaciones y Letras UDP, consultado el 21 de noviembre de 2021, disponible en:

https://www.youtube.com/watch?v=blpkxFSfT2s\&ab_channel=FacultadComunicaci $\% \mathrm{C} 3$ $\%$ B3nyLetrasUDP

VALdivieso, Mercedes. La brecha. Santiago, Zig-Zag, 1961.

"Entrevista realizada por Lucía Guerra en agosto de 1981". En "Feminismo y subversión en La brecha de Mercedes Valdivieso". Lucía Guerra-Cunningham, Literatura chilena, creación y crítica XXI,1982, pp. 5-9.

WitTIG, MoniQue. El pensamiento heterosexual y otros ensayos. Madrid, Egales, 2006. 